\title{
DJ Jesus Luz?! Controvérsias, capital subcultural e performance de gosto em uma cena de música eletrônica
}

\section{DJ Jesus Luz?! Controversies, subcultural capital and taste as performance in an electronic music scene}

Simone Pereira de Sá

Doutora em Comunicação e Cultura pela Universidade Federal Fluminense, professora do Programa de Pós-Graduação em Comunicação da Universidade Federal Fluminense. Bolsista do CNPq - PQ 1D.

<sibonei.sa@gmail.com>

\section{Beatriz Polivanov}

Doutora em Comunicação pelo Programa de Pós-Graduação em Comunicação da Universidade Federal Fluminense e também professora do mesmo.

<beatriz.polivanov@gmail.com>

\section{RESUMO}

$\mathrm{O}$ artigo tem como objetivo central discutir questões de gosto, valor, e disputas simbólicas (Bourdieu, 2008; Thornton, 1996; Frith, 1996) de atores de uma cena de música eletrônica brasileira (Straw, 1991). Para tal, focamos nossa análise no caso do modelo Jesus Luz, que namorou Madonna e posteriormente se tornou DJ, suscitando uma série de polêmicas relacionadas à autenticidade de suas performances. O caso de Jesus Luz será tratado como uma controvérsia (Latour, 1994; 2005) que nos permite apreender a performance de gosto (Hennion, 2003; 2007) dos atores da cena eletrônica "em ação".

Palavras-chave: Cena Musical. Controvérsia. Capital subcultural.

\begin{abstract}
The paper aims to discuss issues on taste, value and symbolic disputes (Bourdieu, 2008; Thornton, 1996 e Frith, 1996), analyzing the discourses of participants from a Brazilian electronic music scene (Straw, 1991). In order to do so, we focus our analysis on the case of Brazilian model Jesus Luz, who was Madonna's boyfriend and later became a DJ, raising disputes related to the authenticity of his performances. The "case" of Jesus Luz will be treated as a controversy (Latour, 1994; 2005) that allows us to grasp the performance of taste (Hennion, 2003; 2007) of the actors "in action".
\end{abstract}

Keywords: Music Scene. Controversy. Subcultural Capital.

\section{Introdução}

Durante o ano de 2009, o mundo pop foi apresentado a mais uma criação de Madonna: Jesus Luz, o jovem modelo brasileiro que ganhou notoriedade por tornar-se, por alguns meses, o namorado da cantora, que o conheceu durante sua turnê no ano anterior. Além dos irresistíveis trocadilhos com os nomes de ambos, a beleza do rapaz e a diferença de idade do casal foi o assunto predileto da mídia por um par de meses. 
Entretanto, Jesus não se contentou em se tornar a maior celebridade da última semana da década passada. Buscando estender seus cinco minutos de fama, o modelo tornou-se DJ, ator de novela da Globo e permanece, ainda hoje, seis anos após o episódio, sob os holofotes das revistas e blogs de celebridades e em atividade como DJ'.

Segundo a Revista Época de janeiro de 2015, Jesus se mantém com a agenda de DJ lotada: "Na próxima semana ele se apresenta em Nova York e Miami, onde lança o clipe da sua nova música, Electrified, que já está circulando no Youtube e, em breve, poderá ser visto também na TV fechada"2.

Contudo, ainda que Jesus Luz se mantenha sob os holofotes da mídia, sua reputação como DJ está longe de ser aceita consensualmente pela cena3 eletrônica brasileira, sobretudo a exigente cena paulistana. Nesta cena, o DJ despertou rejeição e gerou uma série de polêmicas relacionadas à sua (falta de) competência para mixar ${ }^{4}$ e produzir músicas, às suas performances consideradas por integrantes "da cena" como exageradas e cafonas, além da súbita fama de DJ superstar obtida às custas da exploração de seu relacionamento com uma celebridade - sobretudo no momento em que ganhou a capa da revista Mixmag 5 em 2010.

Cabe observar que a revista explora exatamente estas polêmicas, tanto na sua própria capa através da frase "Jesus Luz - Superstar DJ, será?" e do header de outra matéria da mesma edição, no qual se lê "Tocadisco": "Jesus não tem a

1 Ver, por exemplo, as seguintes matérias do site EGO, no portal do G1, ligado à Rede Globo e especializado em notícias sobre celebridades e "famosos": "Jesus Luz apoia campanha de doação de sangue" (12/06/2014); “Sem camisa, Jesus mostra equilíbrio durante exercício" (18/06/2014); "Jesus Luz posa em clima quente e tropical em editorial de moda (05/11/2014)"; "Jesus Luz se apresenta como DJ sob os olhares da namorada" (21/12/2014) - dentre outras. Disponível em: < http://ego.globo.com/ famosos/tudo-sobre/jesus-luz.html>. Acesso em: 29 mai. 2015.

2 Disponível em: <http://epoca.globo.com/colunas-e-blogs/bruno-astuto/noticia/2015/01/bjesusluzb-que-mantem-relacoes-com-o-filho-de-madonna-lanca-clipe-gravado-na-suica.html>. Acesso em: 31 maio 2015.

3 Partindo da discussão de Straw (1991), entendemos as cenas como espaços onde coexistem a diversidade de práticas musicais que interagem de formas múltiplas, através de diferentes trajetórias de troca e fertilização.

4 Definimos a mixagem como categoria central para a avaliação da qualidade de um DJ na discussão da próxima seção.

5 Revista bimestral; edição número 4; abril/maio 2010 (ver anexo 1). A referida revista - Mixmag Brasil - se autointitula "a versão latina da maior revista sobre cultura clubber e música eletrônica do mundo: MIXMAG", que surgiu na Europa na década de 1980 como "a fonte para os baladeiros de plantão, os DJs/Produtores e para todos os interessados em e-music de qualidade". Ainda que a revista seja classificada pelos informantes deste trabalho como "mainstream", popular, ela também é reconhecida por eles como um importante meio de divulgação da cena.

6 "Tocadisco" é o nome artístico do DJ e produtor alemão de música eletrônica Roman Böer, que é tido como o "inimigo público número 1 de Jesus e o rei do electrohouse", expressão usada pelo jornalista 
menor ideia", e também na matéria principal dentro da revista, cujo título é "O rapaz por trás da polêmica". A reportagem dentro da revista aborda também esses assuntos, mas busca dar espaço para que Jesus fale sobre si mesmo e sobre sua carreira de DJ, buscando não emitir juízo de valor. Uma das frases finais da matéria repete a pergunta da capa da revista ("Jesus Luz - Superstar DJ, será?") e responde: "O mercado e o público é que vão decidir".

A polêmica repercutiu também nos sites de redes sociais. Por exemplo, no Youtube, onde há vídeos que mostram uma das apresentações de Jesus em um clube noturno no Brasil, na qual se vê outro homem mixando as músicas enquanto o modelo faz pose para o público, ignorando o fone de ouvido em geral necessário para as mixagens ${ }^{7}$. Além disso, blogs e sites questionam também o lançamento, em 2011, pela Warner Music, do álbum de Jesus, intitulado "From light" - com contrato supostamente obtido por intermédio de Madonna8.

Assim, a opinião dominante entre frequentadores da cena paulistana de música eletrônica9 é a de que Jesus "enfraquece a cena", por três razões principais: 1) por corroborar a ideia de que "qualquer um pode ser DJ hoje em dia", mesmo sem ter talento para tal; 2) por tirar o foco do trabalho em si mixagens e seleções musicais - e colocá-lo na imagem e popularidade do DJ e 3) por se entender que ser um "DJ celebridade" não teria autonomia para realizar seu trabalho de DJ, uma vez que estaria atrelado principalmente às demandas e necessidades do mercado, de"se vender"10.

cultural especializado em música eletrônica Ivi Brasil no post "dj jesus luz; 'we came from light'; kaos" em seu blog. Disponível em: <http://maisumteko.wordpress.com/2010/06/10/dj-jesus-luz-we-came-fromthe-light-kaos/>. Acesso em: 17 maio 2015.

7 Um desses vídeos é intitulado "DJ Jesus Luz é uma "farsa"!" Disponível em: <http://vodpod.com/ watch/2336926-dj-jesus-luz-uma-farsa>. Acesso em: 27 maio 2015.

8 Como mostra, dentre tantos outros, o post "Madonna consegue contrato para Jesus Luz em gravadora", disponível no blog Yes Pop: <http://www.yespop.com.br/2010/02/madonna-conseguecontrato-para-jesus.html>. Acesso em: 20 maio 2015.

9 Cabe ressaltar que os frequentadores aos quais nos referimos são sujeitos que moram na cidade de São Paulo e que participam da cena de música eletrônica desde seus primórdios, no final da década de 80 , início da década de 90, o que lhes confere certo status de "pioneiros" da cena. Dentre aqueles com os quais dialogamos estão desde produtores musicais e DJs até jornalistas culturais e fotógrafos especializados em cobrir as festas. Suas percepções são fruto da pesquisa de campo conduzida por Beatriz Polivanov, durante o ano de 2010).

10 Para a elaboração deste artigo, utilizamos ainda como dados discursos de atores sociais da cena de música eletrônica veiculados em aparatos midiáticos diversos, como revistas impressas especializadas, sites de notícias, blogs e sites de redes sociais, dentro de um recorte temporal que vai desde 2009 a 2015, com notícias recentes dos blogs "de celebridade", tais como: Ego (ver nota 2) e a entrevista à Revista Época, de 9/1/2015. Disponível em: <http://epoca.globo.com/colunas-e-blogs/bruno-astuto/ noticia/2015/01/bjesus-luzb-que-mantem-relacoes-com-o-filho-de-madonna-lanca-clipe-gravado-nasuica.html>..Acesso em: 29 maio 2015, que demonstram a permanência de Jesus Luz na categoria de "DJ Superstar." 
Conforme discutido anteriormente (Pereira de Sá, 2003), o que está em jogo, nesta polêmica, à luz da sociologia da música, é a discussão sobre processos de rotulação, valores, legitimidade e disputa simbólica entre os atores de uma cena musical. Entretanto, partindo deste reconhecimento em torno da disputa simbólica, interessa-nos ir além e compreender os processos através dos quais os atores de uma cena constroem hierarquias e modos de legitimação dentro da cultura popular, acumulando capital sub-cultural ${ }^{11}$ (Thornton, 1996).

Desta maneira, central para a discussão é o argumento de que o gosto não é um elemento estável, construído "de uma vez e para sempre" a partir da classe social, e "imposta" aos indivíduos, conforme propôs Bourdieu. Pelo contrário, a dimensão performática da noção de gosto e o papel dos diversos mediadores (Hennion, 2003; 2007; Amaral e Monteiro, 2013; Pereira de Sá, 2014) envolvidos no processo performativo é central para a nossa discussão.

Articulada a esta primeira discussão, caberia destacar também uma segunda premissa oriunda da Teoria Ator-Rede relacionada à noção de controvérsia, entendida como o momento privilegiado para observarmos os actantes em ação. "Momento em que a complexidade das relações sociais se revela na infinidade dos mediadores, nas relações de forças desiguais, nos embates e finalmente na sua estabilização, quando a controvérsia se transforma numa 'caixa-preta'"' (Pereira de Sá, 2014, p. 547).

Assim, o"caso"Jesus Luzserá abordado neste artigo como uma controvérsia que nos permite vislumbrar os gostos da cena de música eletrônica em ação, contribuindo ao mesmo tempo para entendermos como se dão concretamente as dinâmicas de legitimação e conquista/perda de capital, atreladas à noção de autenticidade. Para este fim, o trabalho organiza-se em duas partes: na primeira, resgataremos o contexto de consolidação da figura do DJ e seus valores; e na segunda, analisaremos as controvérsias em torno do caso Jesus Luz.

\section{Negociando a música eletrônica}

Os anos 70, poca do surgimento da disco music, podem ser tomados como um momento fundador da cultura da música eletrônica. Essa é a década em que o DJ sai do rádio, passando a trabalhar nas pequenas discotecas, ou clubs,

11 Proposta por Thornton (1996) no contexto de sua análise das fronteiras da cultura da música eletrônica inglesa, nos anos 90, a noção enfatiza, à luz do debate de Bourdieu sobre capital cultural, a importância de um capital bastante específico. Trata-se daquele conhecimento adquirido pelos agentes no contato com a(s) mídia(s), e que se remete a consumir informação exclusiva e produtos culturais "certos" tais como discos, shows, lugares para dançar, roupas, além do conhecimento das "pessoas que importam". Trata-se, portanto, do conhecimento exclusivo que vai transferir status ao agente, abrindoIhe portas e garantindo-Ihe um lugar hierárquico privilegiado nesta cultura de gosto. 
desenvolvendo um estilo diferente de apresentação. Naquele momento, ele passa a ter um contato presencial com sua audiência, que avalia sua atividade em uma pista de dança que enche ou se esvazia a partir de sua performance musical. Além disto, o DJ começa a mixar, ou seja, a misturar elementos de dois discos rodando ao mesmo tempo em um par de toca-discos, criando assim uma sequência sonora ininterrupta, onde o sentido de cada música passa a ser avaliada dentro do todo e colocando o DJ no papel de mediador12 de um evento efêmero e singular (Brewster e Broughton, 2000).

Seu espaço de mediação torna-se ainda maior quando ele se torna também produtor, passando a lançar seu próprio material. Dessa forma, aos efeitos produzidos ao vivo, somam-se aqueles pré-produzidos em estúdio, dos quais destacaremos a prática do sampling e do remix.

A prática do remix refere-se à adequação de uma música à pista de dança. Assim, o DJ utiliza-se de seus conhecimentos técnicos para produzir uma versão adequada à pista, alterando elementos como ritmo, textura, instrumentação e andamento.

Um segundo procedimento baseado na reutilização de sonoridades existentes é o sampling ${ }^{13}$, quando faixas são compostas com a utilização de fragmentos musicais pré-gravados - um refrão, uma célula rítmica, um riff de guitarra - de autoria de outros compositores.

Em conjunto, o sample e o remix tornam-se procedimentos estéticos centrais, consolidando a música eletrônica em oposição aos valores do pop rock. Assim, no lugar de uma escuta "personalista", que valoriza o ato de comprar discos, decorar suas letras, ir a shows e cultuar suas estrelas, temos uma outra prática que se apoia na figura do DJ e em produtores batizados com codinomes ou múltiplos projetos musicais, que não hesitam em quebrar a unidade original da canção ou retirá-la da sequência do álbum de origem, com vistas a intensificar a experiência efêmera e sensorial da pista de dança ${ }^{14}$.

Nos anos 80, a revitalização da disco music acontece na cena musical das cidades americanas de Chicago, Detroit e Nova York. Com o barateamento de equipamentos de produção sonora, os DJs passam a combinar texturas eletrônicas de sintetizadores produzindo singles - discos com poucas faixas

12 Entendemos a noção de mediador a partir da teoria Ator-Rede como o ator que altera, desvia e produz diferença numa rede sociotécnica constituída por atores humanos e não-humanos. Ver: Latour (1993; 2005); Callon e Law (1997).

13 As origens dessas práticas remetem respectivamente ao dub jamaicano, no caso do remix, e ao hip-hop, no caso do sampling. Para detalhes, ver Shapiro (2000).

14 Para o aprofundamento da discussão sobre esses procedimentos, ver Pereira de Sá (2003). 
feitos especialmente para serem mixados em uma pista de dança - reforçando a noção de DJ produtor. Ao mesmo tempo, este material passa a ser distribuído por pequenos selos que conseguem chegar à Europa, evidenciando a possibilidade de consolidação de um circuito segmentado que passa a sustentar a música eletrônica.

Ao longo dos anos 80 , esta cena não só se consolida, mas também caminha na direção da maior segmentação do público e especialização dos DJs. Assim, ao invés da coexistência de sonoridades em um mesmo espaço - comum nos anos 70 - a cena se fragmenta em uma grande quantidade de subgêneros tais como drum 'n'bass, trance e gabba, concomitantemente ao surgimento das raves londrinas - festas ilegais que ocorriam em locais abandonados, nos arredores de Londres e que evitavam a divulgação pelos canais da grande mídia, a fim de manterem a polícia e as autoridades à distância (Thornton, 1996).

Inserido neste contexto, o DJ incorpora também a representação de uma figura anti-establishment, ligado ao underground - entendido como o lugar do experimentalismo e da vanguarda - em oposição ao mainstream, considerado o lugar do massivo.

É neste panorama que o gênero passa a reivindicar sua autonomia, criando uma identidade própria, que se articula não só a regras musicais, mas também a práticas sociais, valores e personagens-chave. A partir de então, falar em música eletrônica significa muito mais do que a referência a uma sonoridade. Trata-se de uma cultura que tem como mediador central o DJ - agora com um status muito diferente daquele que ele tinha no rádio.

Neste novo cenário, três categorias passam a sintetizar a discussão sobre o valor dos DJs: repertório, técnica e feeling ${ }^{15}$ (Pereira de Sá, Garson e Waltenberg, 2008). Isto significa que para ter sua qualidade reconhecida, independentemente do sub-gênero que toca, o DJ tem que possuir bons discos, saber quando identificar o "clima da pista" para tocar os "discos certos" na "hora certa" e que, para assim fazê-lo, precisa ter o domínio técnico que vai permitir que misture as faixas sonoras num fluxo ininterrupto para a manutenção do "clima".

Entretanto, se retomamos a noção de performance de gosto anteriormente apontada, podemos sugerir que esses critérios não são dados a priori, nem "vêm de dentro" mas estão atrelados ao contexto discutido anteriormente, quando uma rede sócio técnica constituída por mediadores humanos - tais como outros

15 Uma rápida consulta ao site rraurl já revela a importância destas categorias, que aparecem com insistência na discussão dos participantes do fórum. Também a introdução do livro Last Night a Dj Saved My Live - The History of the Disc Jockey (Brewster e Broughton, 1999) sublinha este trinômio como básico. 
DJs, o público, os empresários das casas noturnas, os jornalistas especializados, dentre outros - e também técnicos, tais como os vinis ou CDs, os aparelhos de mixagens, as caixas de som, o espaço acústico das pistas de dança - consolida a música eletrônica como gênero, estabelecendo, simultaneamente, os critérios a partir dos quais o DJ passa a ser avaliado - e que permanece instável e em disputa na atualidade, conforme o caso Jesus Luz demonstra.

Autenticidade e capital subcultural na cena da música eletrônica: demarcando fronteiras através da distinção

A partir do trabalho de Thornton, autores como Pereira de Sá e De Marchi (2005); Pereira de Sá, Garson e Waltenberg (2008); Garson (2009); Fontanari (2004) e Feitosa (2002) buscaram entender - através de objetos e ângulos de pesquisa distintos - como se davam, na práxis, os conflitos e disputas simbólicas que demarcavam fronteiras e posições sociais dentro de diferentes cenas de música eletrônica. Dialogando com estes trabalhos, estamos aqui interessadas em investigar essa dinâmica em uma cena específica: a de produtores musicais, DJs e outros atores que têm suas vidas profissionais ligadas à música eletrônica, que moram e frequentam as festas de São Paulo, e que "vivem" a cena desde o seu início, ou seja, que são participantes "antigos" dela, desde sua suposta "origem" no Brasil.

Além disso, estamos focando neste trabalho um aspecto específico dessa dinâmica: as disputas simbólicas por capital subcultural relacionado à autenticidade, concretizadas no discurso dos atores observados, da referida revista Mixmag e em sites e blogs de música eletrônica. Conforme apontamos, o modelo/DJ Jesus Luz tem suscitado uma série de polêmicas entre os participantes de cenas de música eletrônica que dizem respeito, principalmente, a: 1) quem pode pertencer a essa cena e 2) como deve ser esse pertencimento, estando ambas as questões relacionadas às noções correlatas de legitimidade e de autenticidade, esta última entendida por Frith como uma "qualidade percebida de sinceridade e comprometimento"16 (1996, p. 71, tradução nossa). O"autêntico" seria um "elemento essencial na constituição das relações sociais estabelecidas entre os participantes da cena, no estabelecimento de hierarquias, lógicas de pertencimento, inclusão e exclusão" (Feitosa, 2002, online).

Também abordando a questão, Garson observa: "mesmo na análise de (...) cenas musicais, cujos códigos estão a toda a hora se modificando, a necessidade de se soar verdadeiro, ainda é bastante importante" (2009, p.

16 Tradução para "Perceived quality of sincerity and commitment". 
43). E, em se tratando de cultura popular, não há (e provavelmente não são desejadas) instituições formais que possam ensinar aos sujeitos como "soar verdadeiro" ou "ser autêntico", ao contrário de outras competências/habilidades (como aprender a tocar um instrumento musical) que podem ser aprendidas institucionalmente. Dessa forma, "essa competência só se adquire mediante o pertencimento a esses grupos e engajamento em seus rituais que implicam em maneiras especificas de se utilizar bens específicos" (Garson, 2009, p. 50).

E para pertencer ao "grupo" é necessário não apenas possuir capital econômico - de forma a poder frequentar as festas, comprar músicas, roupas etc. - mas principalmente capital (sub)cultural, "ou seja, conhecimento sobre as regras e valores específicos que cada grupo constrói para si, e que asseguram a seus membros prestígio e respeito" (idem), levando, assim, à legitimidade e poder de fala. Isto é, importam mais as maneiras pelas quais alguém se apropria de determinado bem ou serviço do que o produto por si só.

O que vemos no caso de Jesus Luz é, portanto, um ator que parece não deter capital cultural, simbólico, para entrar ou pertencer à cena da música eletrônica com a qual estamos trabalhando aqui. Ou seja: mesmo com a imensa popularidade de Madonna como diva pop e sua legitimidade como divulgadora da cultura das pistas de dança, seu capital cultural não é transferível automaticamente.

Assim, Jesus parece não ter introjetado um certo habitus - entendido aqui, a partir de Bourdieu (2005), como um conjunto de práticas e valores adquiridos, formas de pensar relacionadas às formas de se comportar que os sujeitos apreendem, cotidianamente, via experiência, convívio e aprendizagem e que, no nosso caso, está bastante ligado à performance do sujeito - de ser DJ.

Isso fica evidenciado quando os sujeitos observados neste trabalho ridicularizam as apresentações de Jesus, quando ele faz uma seleção musical tida como "pobre", uma vez que seriam músicas já muito tocadas por outros DJs, e de"mau gosto"; quando ele conta com o auxílio de outro DJ para tocar; quando ele fica em pé em cima da mesa de equipamentos, batendo palmas para "agitar" o público e quando há rumores de ele toca com CDs já mixados - tirando, assim, a necessidade de mixar as músicas ao vivo e mostrando, supostamente, sua incapacidade para tocar.

Além das apresentações, as críticas a Jesus também dizem respeito, por exemplo, às próprias fotos de divulgação (ver anexo 3) que são escolhidas para 
serem colocadas nos flyers ${ }^{17}$ das festas. As fotos ressaltariam a beleza física do modelo/DJ e sua sensualidade, o que é considerado por nossos informantes como algo apelativo, que diminui o valor do artista enquanto $D J^{18}$. $E$, além disso, essas críticas nos remetem também à questão do gosto (Jesus tocaria músicas de "mau gosto", teria "mau gosto" para fazer suas performances e até para escolher suas fotos de divulgação). Ou seja, a questão de como sua imagem é construída parece ser também de extrema importância para sua não legitimação na cena. Conforme explica Garson,

o reconhecimento só ocorre quando os signos consumidos no mercado ganham reconhecimento coletivo, dessa forma têm de ser exibidos e postos à prova tanto na forma de commodities, capital cultural objetificado (roupas, discos, livros, etc.), quanto na forma de discursos, capital cultural incorporado (a qual festa se vai, qual DJ se conhece, qual música se escuta). (Garson, 2009, p. 64)

Retomando as três categorias discutidas acima na construção de valor dos DJs - técnica, repertório e feeling - argumentamos que elas são centrais para a discussão do caso Jesus Luz. Muitas das vezes um DJ pode não possuir uma técnica muito apurada, mas faz extensas pesquisas musicais e sabe compor bons repertórios, além de conseguir "sentir a vibe" (vibração) da pista, o que faz com que sua pouca técnica não afete negativamente suas performances. 0 inverso também pode ocorrer: um DJ pode saber mixar muito bem, mas não ter um repertório tão interessante, por exemplo, sem que isso faça com que ele perca valor na cena. Não obstante, um DJ só é tido como valorizado de fato se conseguir ter alguma habilidade nas três categorias, por mais que uma se sobressaia em relação à outra, conforme ilustra a fala abaixo do DJ e produtor Claudio Silberberg:

independente da técnica de mixagem, ele tem que ter presença do que o público está querendo. Ninguém quer só técnica, o público quer dançar. Conheço muita gente que não sabe mixar, mas consegue animar uma pista porque consegue encaixar uma boa sequência de músicas. Tem que ter 'feeling'. Mas eu, como produtor, só contrato

17 Flyers, nesse contexto, são conteúdos impressos ou digitais de divulgação de festas e/ou artistas. Sua arte visual é considerada uma importante maneira de criação da identidade da festa / evento / DJ. 18 Atualmente há muitas mulheres DJs que, segundo os informantes, apelam para seus atributos físicos para conseguir chamar a atenção do público, seja ao utilizar decotes em suas apresentações, fazer topless durante as mesmas e/ou "se vender", através das fotos de divulgação, como uma mulher "gostosa", em poses sensuais, o que as desqualificaria totalmente como DJs. Essas mulheres possivelmente constituem o grupo de DJs com menos respeito e nenhum prestígio na cena. 
alguém que eu tenha visto tocar ao vivo. E é claro que a mixagem é importantíssima ${ }^{19}$ (Silberberg, [2009], 2015).

Ou seja, para ser valorizado e reconhecido não é necessário que um determinado DJ seja excelente quanto aos três elementos destacados, mas ele(a) certamente não pode ser considerado(a) péssimo(a) simultaneamente nas três categorias, como é, para nossos informantes, o caso de Jesus.

A que talvez fique mais evidente e seja a mais contestada é a questão da técnica. Conforme apontamos acima há uma série de vídeos e comentários na internet que colocam em xeque sua capacidade de operar o mixer e tocar como DJ, como mostra a fala a seguir: "Q bosta...acho q ele nem sabe o q é High, Medium e Low do MIXER...q feio...e aqueles caras ali mixando pra ele q feio...e pior não sei se é o público aplaudindo isso, ou os caras q contratam ele..." ${ }^{\prime 20}$.

$\mathrm{Na}$ ocasião em que Jesus foi convidado a tocar no programa "Altas Horas" liderado por Serginho Groisman no canal Globo ${ }^{21}$, sua performance suscitou novamente polêmica quanto à sua técnica, uma vez que se aventou a possibilidade de os equipamentos estarem desligados e o set ${ }^{22}$ ter sido um CD gravado, tocado pela produção do programa, enquanto Jesus teria apenas fingido que estava tocando. Esse evento foi motivo de debates em sites de redes sociais, blogs e até mesmo em sites de notícias como o Folha.com ${ }^{23}$. Enquanto uns defenderam a apresentação de Jesus, utilizando argumentos para provar que o equipamento estava ligado e que ele tocou "de verdade", outros viram no episódio mais uma "prova" de que Jesus não sabe de fato tocar, conforme mostra a fala abaixo:

Cara-de-pau tem limite... ou não. O ex-namorado de Madonna, Jesus Luz, protagonizou um momento de vergonha alheia na madrugada de sábado (17), na Rede Globo. Convidado no programa Altas Horas, de Serginho Groisman, Jesus afirmou que está investindo mais em sua carreira de DJ do que como modelo. Até aí tudo bem. Mas em

19 Fala publicada em 17/10/2009.

20 Comentário postado em 22/10/2009, disponível em: <http://vodpod.com/watch/2336926-djjesus-luz-uma-farsa>. Acesso em: 30 maio 2015. Ver também anexo 2.

21 O programa foi ao ar no dia 17 de setembro de 2011 e os registros desta performance podem ser encontradas no Youtube. A performance continua a receber comentários negativos até a presente data, passados quatro anos.

22 Conjunto de músicas tocadas e mixadas em uma apresentação de DJ.

23 "Serginho Groisman nega "farsa" de Jesus Luz no "Altas Horas"'!. Disponível em: <http://f5.folha.uol. com.br/televisao/979525-serginho-groisman-nega-farsa-de-jesus-luz-no-altas-horas.shtml>. Acesso em: 27 maio 2015. 
seguida, ao ser convocado para tocar no encerramento do bloco, Luz 'dublou' uma discotecagem. Isso fica evidente pelo fato de que as câmeras do programa focalizam a CDJ, que está desligada ${ }^{24}$ (Vírgula, [2011], 2015).

No que tange ao repertório que Jesus toca em suas apresentações como DJ, fica claro que ele não se afilia a uma estética sonora tida como mais underground. Ao contrário, Jesus costuma tocar faixas de bandas pop como Black Eyed Peas e de DJs considerados mainstream, como David Guetta. Além disso, apresenta-se com frequência em eventos e/ou festas considerados "cooptados", cujo objetivo principal não seria a música em si e sua fruição, mas sim outros valores como "pegação", ostentação de capital econômico, aparição na mídia, etc., como micaretas, camarotes para pessoas VIPs e clubes noturnos para pessoas classificadas como "patricinhas" e "mauricinhos", ou seja, pessoas de classe social elevada que estariam interessadas nesses valores mais do que na música em si.

Por fim, o terceiro elemento - feeling de pista - é tido por muitos como uma habilidade que Jesus também não possui. Mesmo quando os sujeitos aceitam que suas apresentações costumam atrair e agradar muito público, isso só ocorreria ou pelo fato de esse público querer agradar à Madonna (enquanto ela ainda estava namorando Jesus) ou por ser considerado um público sem capacidade para distinguir o que é "bom" do que é "ruim", como sintetiza a fala abaixo:

O cara é travado, não tem talento nem carisma! (...) Esse cara está sendo chamado de FAKE por todos os DJS fora e dentro do Brasil. E agora? Se como modelo ele não conseguia nada - até conhecer Madge [Madonna] - como DJ ele só toca no Brasil, pra alguns desavisados que gostam de jogar dinheiro no lixo! La fora, ele só toca pros amigos da Madge, porque americano não gosta de fakes ${ }^{25}$ (Vodpod, 2015).

\section{Cinco anos depois...}

Conforme mencionado, a revista Época, da empresa Globo, traz em seu número de janeiro de 2015 uma entrevista com Jesus Luz, cujo título é: "Jesus Luz, que mantém relações com o filho da Madonna, lança clipe gravado na Suíça". Segue-se a foto de um sorridente Jesus Luz, num cenário de neve, abraçado a modelo Helena Wladim - modelo muito parecida com Madonna

24 Post no site Vírgula, publicado em 19/09/2011.

25 Comentário postado em 22/10/2009. 
aos 30 anos. As referências à sua "madrinha" artística não param por aí, uma vez que a matéria menciona - não sem ambiguidades sexuais - que ele "mantém relações com Rocco, filho de Madonna, jovem que é fã de música eletrônica e vive trocando figurinhas com Jesus nas redes sociais". Enfatizando o "sucesso" da carreira do modelo/ator/Dj, a matéria destaca sua agenda lotada para 2015, com apresentações marcadas para Miami e Nova York.

$\mathrm{Na}$ entrevista, Jesus sublinha a sua dedicação à carreira de DJ: "Me dediquei, estudei e dei prioridade à carreira de DJ e produtor. O reconhecimento do público e do meio, tanto no Brasil quanto lá fora, é resultado da minha dedicação e do amor dos meus fãs e admiradores".

Enquanto isto, o video de sua atuação "fake" permanece sendo visto e comentado negativamente no Youtube, demonstrando que a controvérsia não foi estabilizada. Como, por exemplo @gabrielmartins, que comenta em 29 de abril de 2015:

Os caras são tão merda e fúteis, que não se preocupam nem com a própria imagem. Que se proponha a fingir igual a um idiota, pq tb não sabe fazer outra coisa, mas pelo menos peça a produção que ligue o equipamento na energia para tentar enganar!! (Youtube [vídeo], 2015).

\section{Considerações finais}

Conforme já destacou Frith (1996), gosto não só se discute, mas é também um dos principais marcadores da experiência de fruição dos produtos culturais. Entretanto, o gosto não é nem uma expressão intrínseca ao sujeito nem à obra, no sentido de um conjunto de valores fixos, estáveis e adquiridos/percebidos de uma vez e para sempre - tal como a noção de que "gosto vem de berço", por exemplo, sugere. Pelo contrário. A partir de autores que enfatizam a dimensão performativa da valoração baseada no gosto, tanto quanto o caráter coletivo, compartilhado e mediado deste processo, buscamos entender como se dão as disputas em torno do reconhecimento do modelo Jesus Luz como DJ e quais são os elementos acionados pelos atores para desqualificá-lo como um DJ "de verdade".

Dentre esses elementos ressaltamos sua suposta incapacidade técnica de mixagem - que estaria atrelada tanto a uma habilidade cognitiva e motora, quanto de "ter um bom ouvido", sensível à música -, vinculada também a uma performance enquanto DJ que seria de "mau gosto", apelativa e popular, e seu lugar enquanto celebridade - ou talvez, melhor ainda, subcelebridade -, que 
Ihe denotaria um caráter mainstream, cooptado pelo sistema midiático, em oposição ao que seria um caráter artístico.

Destacamos, assim, que os complexos modos através dos quais os sujeitos buscam delimitar quem pertence a determinada cena musical e quem detém capital subcultural na mesma são marcados por uma dimensão ao mesmo tempo simbólica das práticas relacionadas à performance e discussão de gosto e também material, uma vez que passam tanto pelos objetos produzidos e consumidos quanto pelas formas como esses materiais são apropriados pelos atores. Ao mesmo tempo, trata-se de um work in process, um evento, sempre inacabado, sempre em disputa, onde atores inseridos numa rede sócio-técnica atualizam seus afetos e sensações a partir de mediações bastante heterogêneas.

Comparando amantes de vinhos e de música, Hennion sintetiza a questão, quando observa que ambos os grupos nos permitem perceber o gosto em processo ou ação:

\begin{abstract}
Não se trata de gostar de música ou de ser um apreciador de vinhos, mas de ser tocado por esta peça ou de gostar desta garrafa, aqui, agora, com estas pessoas: uma estranha atividade, cujas condições são continuamente discutidas pelos próprios amantes/amadores. Atividade que se relaciona intimamente aos momentos, lugares, oportunidades: gosto é, portanto, não somente uma atividade, é um evento, extremamente sensível à problemática relação entre - como eles |os informantes| dizem - uma combinação de circunstâncias ${ }^{26}$. (Hennion, 2003, p. 90)
\end{abstract}

Assim, seguindo os rastros de diversos atores da cena eletrônica, nosso objetivo foi captar esta disputa em sua complexidade processual e inacabamento essencial, mantendo em aberto a definição sobre os limites de uma cena, dos lugares de fala de seus atores e os parâmetros de legitimidade e autenticidade cultural.

26 It's not about liking music or being a wine taster, but being touched by this piece or liking this bottle, here, now, with these people: a strange activity, the conditions of which are continuously discussed by amateurs themselves. It relies closely upon moments, places, opportunities: taste is not only an activity, it is an event, over-sensitive to the problematic relationship between - as they nicely say - a combination of circumstances" (tradução nossa). 


\section{Anexos}

Anexo 1 - Capa da revista Mixmag/Brasil; edição número 4; Abril/Maio, $2010^{27}$.

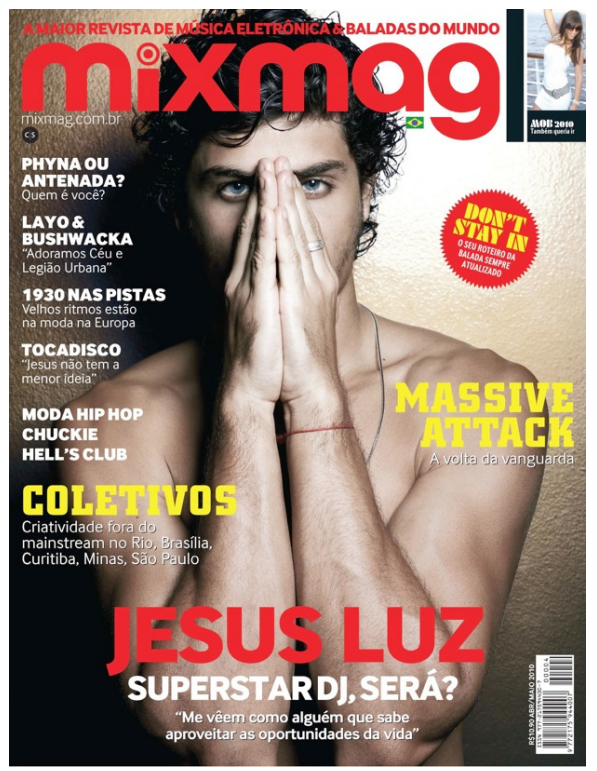

Anexo 2 - Imagem mostrando outra pessoa supostamente tocando no lugar de Jesus Luz durante apresentação em Santa Catarina ${ }^{28}$.

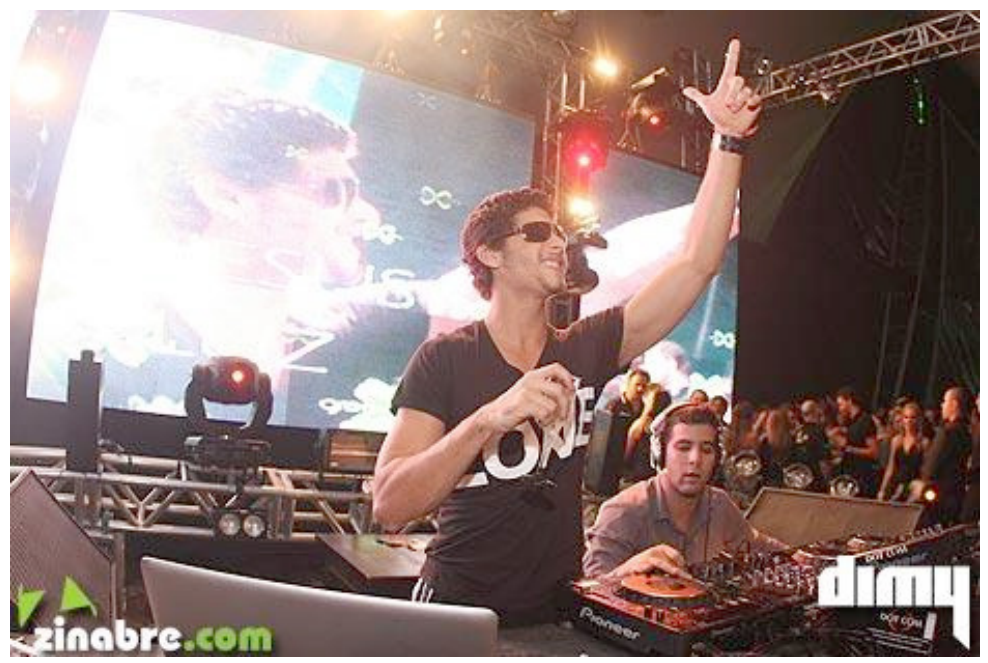

27 Disponível em: <http://36.media.tumblr.com/tumblr 10ayxkGm3D1qbq3pao1 1280.jpg>. Acesso em: 27 set. 2015.

28 Disponível em: <http://www.desaforo.com/2009/10/jesus-luz-fotos.html> e outros endereços. Acesso em: 27 set. 2015. 


\section{Anexo 3 - Flyer da festa Ipanema Music Festival ${ }^{29}$.}

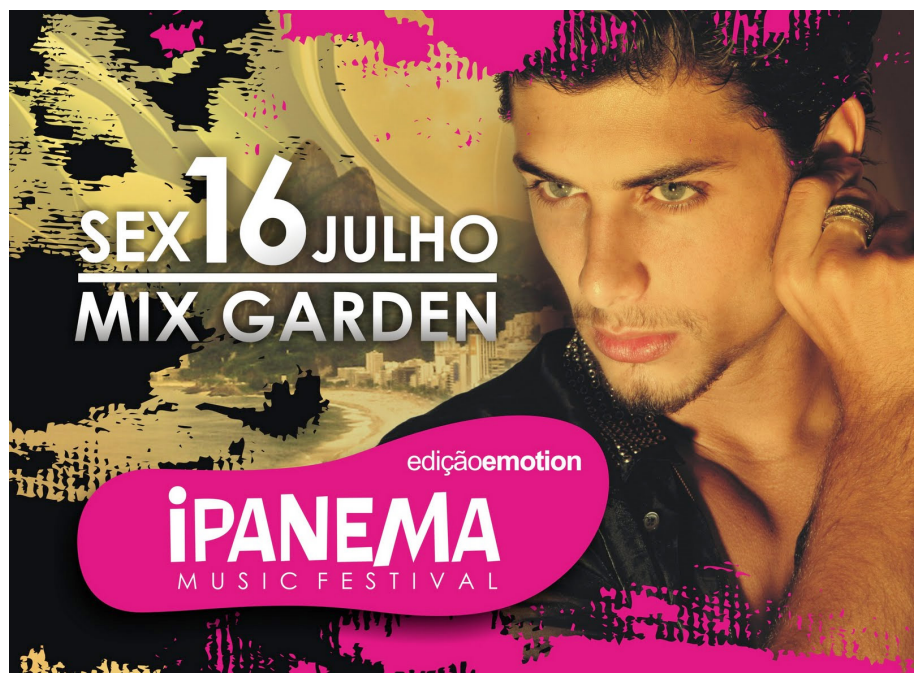

\section{Referências}

AMARAL, Adriana; MONTEIRO, Camila. "Esses roquero não curte": performance de gosto e fãs de música no Unidos Contra o Rock do Facebook. In: XXI Compós, 2012, Juiz de Fora. Anais do XXI Encontro Anual da Compós. Juiz de Fora: UFJF, 2012, p. 1-20.

BOURDIEU, Pierre. $\boldsymbol{A}$ distinção: crítica social do julgamento. São Paulo: EDUSP; Porto Alegre: Zouk, 2008.

A economia das trocas simbólicas. São Paulo: Perspectiva, 2005.

BREWSTER, Bill; BROUGHTON, Frank. Last night a DJ saved my life. The history of the disc jockey. Nova York: Grove Press, 2000.

CALLON, Michel; LAW, John. After the individual in society: lessons on collectivity from science, technology and society. The Canadian Journal of Sociology, v. 22, n. 2, p. 165-182, 1997.

FEITOSA, Ricardo. Perspectivas de abordagem sobre "autenticidade"e "originalidade" na cena de música eletrônica. In: Seminário de Ciberpesquisa da Universidade Federal da Bahia, Salvador, 2002. Disponível em: <http://www.pragatecno. com.br/autenticidade.doc>. Acesso em: 27 set. 2015>.

FONTANARI, Ivan. Música eletrônica e identidade jovem: a diversidade do local.

29 Disponível em: <http://www.muza.com.br/2010/05/festival-que-trara-jesus-luz-para.html>. Acesso em: 27 set. 2015. 
In: V Congresso da IASPM-AL, 2004, Rio de Janeiro. Anais do V Congresso Latinoamericano da Associação para o Estudo da Música Popular. Rio de Janeiro: UniRio, UCAM e PUC-Rio, 2004, p. 01-07. Disponível em: <http://www. iaspmal.net/wp-content/uploads/2011/12/IvanPaoloFontanari.pdf> Acesso em: 27 set. 2015.

FRITH, Simon. Performing Rites. On the Value of Popular Music. Cambridge: Harvard University Press, 1996.

GARSON, Marcelo. Quem é o melhor dj do mundo? Disputas simbólicas na cena de música eletrônica. 2009. 116 f. Dissertação (Mestrado em Comunicação Social) - Programa de Pós-Graduação em Comunicação Social, UFF, Niterói, 2009.

HENNION, Antoine. Music and mediation: towards a new sociology of music. In: CLAYTON, Martin; HERBERT, Trevor; MIDDLETON, Richard. (orgs.). The Cultural Study of music: a critical introduction. 4 ed. Routledge: Nova lorque, p. 80-91, 2003.

HENNION, Antoine. Music Lovers. Taste as performance. Revista Theory, Culture \& Society, online, v. 18, n. 5, p. 1-22, dez. 2007. Disponível em: <https://halshs. archives-ouvertes.fr/halshs-00193124/document>. Acesso em: 27. set. 2015.

LATOUR, Bruno. On Technical Mediation: philosophy, sociology, genealogy. Common Knowledge, Oxford University Press, v. 3, n. 2, p. 29-64, 1994.

LATOUR, Bruno. Reassembling the Social: An Introduction to Actor-Network-Theory. Oxford: Oxford University Press, 2005.

PEREIRA DE SÁ, Simone. Contribuições da teoria Ator-Rede para a Ecologia Midiática da Música. Revista Contemporânea, Salvador, v. 12, n. 3, p. 537-555, set.-dez. 2014.

PEREIRADE SÁ, Simone. Música eletrônica e tecnologia: reconfigurando a discotecagem. In: LEMOS, André; CUNHA, Paulo (orgs.). Olhares sobre a cibercultura. Porto Alegre: Sulinas, 2003.

PEREIRA DE SÁ, Simone; DE MARCHI, Leonardo. Não basta ser DJ: tem que ser underground! Sobre coletivos e comunidades virtuais de música eletrônica no Brasil. Revista FAMECOS, Porto Alegre, v. 1, n. 26, p. 56-67, abr. 2005. Disponível em: <file:///Users/biapoliva/Downloads/3303-10682-1-PB.pdf>. Acesso em: 27 set. 2015.

PEREIRA DE SÁ, Simone; GARSON, Marcelo; WALTENBERG; Lucas. Música eletrônica e rock entre ruídos e riffs: gêneros musicais em tempos de hibridismo. In: BORELLI, Silvia e FREIRE FILHO, João (orgs.). Culturas juvenis no século XXI. São Paulo: EDUC, p. 171-194, 2008.

SILBERBER, Claudio. Disponível em: < http://ego.globo.com/Gente/ 
Noticias/0 "MUL1344394-9798,00-VERDADE+OU+MENTIRA+JESUS+LUZ+ATA $\mathrm{CA}+\mathrm{MESMO}+\mathrm{DE}+\mathrm{DJ}+\mathrm{OU}+\mathrm{E}+\mathrm{TUDO}+\mathrm{ENCENACAO.html}>$. Acesso em: 30 maio 2015.

STRAW, Will. Systems of Articulation, Logics of Change: Scenes and Communities in Popular Music. Revista Cultural Studies, v. 5, n. 3, p. 361-375, out 1991.

THORNTON, Sarah. Club Cultures: Music, Media, and Subcultural Capital. Hannover: University Press of New England, 1996.

VÍRGULA (site). Disponível em: <http://virgula.uol.com.br/ver/noticia/ musica/2011/09/19/284603-jesus-luz-comete-gafe-ao-fingir-ser-dj-na-tv-vejao-video >. Acesso em: 30 maio 2015.

VODPOD (site). Disponível em: <http://vodpod.com/watch/2336926-dj-jesus-luzuma-farsa >. Acesso em: 27 maio 2015.

YOUTUBE [vídeo]. Disponível em: <https://www.youtube.com/ watch? $=$ pehU1B4ITVw>. Acesso em: 29 maio 2015.

Recebido em: 4/6/2015

Aceito em: 21/9/2015

Endereço dos autores:

Simone Pereira de Sá <sibonei.sa@gmail.com>

Universidade Federal Fluminense

Programa de Pós-Graduação em Mídia e Cotidiano/IACS 2

Rua Tiradentes, 148 - Bairro Ingá

CEP: 24210-510

Niterói, RJ, Brasil

Beatriz Polivanov < beatriz.polivanov@gmail.com>

Universidade Federal Fluminense

Programa de Pós-Graduação em Mídia e Cotidiano/IACS 2

Rua Tiradentes, 148 - Bairro Ingá

CEP: 24210-510

Niterói, RJ, Brasil 